\title{
The Epigenetic Basis of Twin Discordance in Age-Related Diseases
}

\author{
PERNILLE POULSEN, MANEL ESTELLER, ALLAN VAAG, AND MARIO F. FRAGA
}

Steno Diabetes Center [P.P., A.V.], 2820 Gentofte, Denmark; Epigenetics Laboratory [M.E., M.F.F.], Spanish National Cancer Centre (CNIO), 28029 Madrid, Spain

\begin{abstract}
Monozygotic twins share the same genotype because they are derived from the same zygote. However, monozygotic twin siblings frequently present many phenotypic differences, such as their susceptibility to disease and a wide range of anthropomorphic features. Recent studies suggest that phenotypic discordance between monozygotic twins is at least to some extent due to epigenetic factors that change over the lifetime of a multicellular organism. It has been proposed that epigenetic drift during development can be stochastic or determined by environmental factors. In reality, a combination of the two causes prevails in most cases. Acute environmental factors are directly associated with epigenetic-dependent disease phenotypes, as demonstrated by the increased CpG-island promoter hypermethylation of tumor suppressor genes in the normal oral mucosa of smokers. Since monozygotic twins are genetically identical they are considered ideal experimental models for studying the role of environmental factors as determinants of complex diseases and phenotypes. (Pediatr Res 61: 38R-42R, 2007)
\end{abstract}

\section{MZ TWINS IN THE STUDY OF AGE-RELATED NON-MENDELIAN DISEASES}

Twin studies have been used extensively in medical research and are instrumental in estimating the relative importance of genetic versus nongenetic components in the etiology of human disease. The rationale underlying classical twin studies is the assumption that MZ twins are genetically identical, whereas DZ twins on average share 50\% of their segregating genes, and are as genetically different or similar as are ordinary siblings. Similarity in MZ and DZ twin pairs can be established by means of concordance rates (for dichotomous variables) and interclass correlation coefficients (for continuous variables). Phenotypes exhibiting a greater degree of similarity in MZ than in DZ twin pairs (i.e. greater concordance or interclass correlation coefficients) are traditionally considered to have a genetic etiological component.

Common age-related complex non-Mendelian diseases such as type 2 diabetes (1), Alzheimer's disease (2), and various cancers, including that of the breast (3) and prostate (4), are all significantly heritable. For example, we, and others, have previously reported concordance rates of type 2 diabetes of 50-92\% among MZ twins (1,5). Most studies of DZ twins

Received November 1, 2006; accepted November 11, 2006

Correspondence: Mario F. Fraga, Ph.D., Epigenetics Laboratory, Spanish National Cancer Centre (CNIO), Melchor Fernandez Almagro 3, 28029 Madrid, Spain; E-mail: mffraga@cnio.es

DOI: $10.1203 /$ pdr.0b013e31803c7b98 have reported significantly lower concordance rates, which is considered evidence of a genetic component in the etiology of Type 2 diabetes. Despite the indication that there is some genetic control, no fully penetrant genes have been identified that in itself fully explains the common form of type 2 diabetes. However, some studies have demonstrated associations between various metabolic defects underlying the development of type 2 diabetes and polymorphisms in several susceptibility genes, such as PPAR $\gamma(6)$, PGC-1 (7), and, most recently, TCF7L2 (8). A fully penetrant dominant disorder would result in $100 \%$ and $50 \%$ concordance in MZ and DZ twins, respectively (9). Incomplete concordance $(<100 \%)$ between MZ twins, even in studies of highly selected subjects, indicates the additional influence of environmental factors. Accordingly, in our study, half of the affected MZ twin pairs were discordant for type 2 diabetes, providing further evidence that the DNA sequence alone cannot explain susceptibility to the disease (1).

\section{ENVIRONMENTAL FACTORS UNDERLYING TWIN DISCORDANCE}

The cause of phenotypic discordance in MZ twins has traditionally been attributed to postnatal environmental factors unique to the individual siblings of the pair (i.e. nonshared environment). Nevertheless, there is increasing evidence that $\mathrm{MZ}$ co-twins may differ due to postzygotic genetic, epigenetic, and prenatal environmental factors, hence challenging the assumption of genetic or epigenetic similarity that underlies the classical twin model. Genetic differences between MZ co-twins arising from point mutations and chromosomal abnormalities are rare and have only been seldom reported. Epigenetic differences include skewed X-chromosome inactivation in female twin pairs and loss of imprinting (10-12). More recently, research has revealed different epigenetic modifications in autosomal genes in MZ twins (13-15). Our recent investigation of global and locus-specific differences in DNA methylation and histone acetylation in young and elderly MZ twins showed that young MZ twin pairs are essentially indistinguishable in their epigenetic markings, whereas elderly MZ twin pairs have substantial variations in several tissues (16). The degree of discordance in epigenetic pattern was related to environmental differences (i.e. arising from lifestyle and time spent together) between twins. Moreover, differences in gene 
expression in the elder twin pairs were four times greater than those observed in the younger twin pairs (16). These findings are of major importance for understanding the results of classical twin heritability and concordance analyses and highlight a potential mechanism by which environmental factors can regulate gene expression. Although the study design could not distinguish whether differences in epigenetic modifications within twin pairs are related to disease discordance, the notion of age-accumulating epigenetic modifications offers an attractive explanation for disease discordance, difference in age of onset, and severity of disease between pairs of twins.

Numerous epidemiologic and metabolic studies of various populations throughout the world have yielded compelling evidence for an association between an adverse fetal environment and the development of glucose intolerance and associated defects of glucose metabolism in adulthood (17-19). It has been hypothesized that a common genotype may result in low birth weight as well as disease in later life (20), and several studies investigating the impact of birth weight on adult disease were unable to adjust for genetic factors. MZ twins who are discordant for disease are an excellent example of how genetically identical individuals can exhibit differences and represent a unique model for studying the contribution and role of environmental factors in disease development. Using this design, we have demonstrated significantly lower birth weights in twins with type 2 diabetes compared with their nondiabetic, genetically identical co-twins. Accordingly, we have verified that the influence of birth weight is independent of genotype and other confounding variables, such as gestational age, maternal age, nutrition and height, sex, and birth order in relation to other siblings (21). In addition, we have recently demonstrated a nongenetic association between birth weight and several pathophysiological mechanisms (e.g. impaired insulin secretion and action) underlying the development of type 2 diabetes in elderly MZ twins $(22,23)$.

The influence of fetal environment on adult disease is thought to be mediated through fetal "programming" (24). This is defined as either an impaired development of a permanent structure or the "new" setting of a physiologic system by an early stimulus or insult operating at a sensitive period that has long-term consequences for function. A more recent expansion of "programming" is the launch of the concept "developmental plasticity," which refers to the ability of a genotype to produce more than one alternative form of structure, physiologic state, or behavior in response to environmental conditions $(24,25)$. The induced changes are believed to be potentially beneficial for short-term survival under conditions of scarce nutritional supply. However, when they are introduced to an abundant food supply in the Western world they lead to development of disease. The pathophysiological and molecular mechanisms underlying the influence of these prenatal and early postnatal environmental factors are to a large extent unknown. However, there is growing interest in the idea that epigenetic processes may play a key role in this puzzle, potentially representing the link between early environmental influences and disease phenotype. Epigenetic modifications regulate a variety of genomic activities, including the expression of genes essential for normal growth, development, and differentiation, without changing the underlying genomic sequence, and, unlike the static DNA sequence, display considerably plasticity.

There is increasing evidence of epigenetic modulation occurring early in life in response to environmental factors (26). Studies of intrauterine-growth-retarded rats have demonstrated that an adverse intrauterine environment is associated with an epigenetically induced down-regulation of key genes regulating $\beta$-cell development, differentiation and function (27). In addition, an adverse uterine environment induced by maternal dietary protein restriction (28) or uteroplacental insufficiency (29) has demonstrated gene-specific changes in methylation state and hence gene expression levels in the liver and kidney in the offspring. Interestingly, maternal behavior can change the epigenomic state of a gene in the offspring. Weaver et al. (30) demonstrated that increased pup-licking, grooming, and arched-back nursing changed the epigenome at the glucocorticoid receptor gene in the hippocampus, resulting in greater expression of the glucocorticoid receptor and an improved response to stress in adult offspring. Furthermore, these molecular and phenotypic changes were shown to be reversible upon central infusion of the histone deacetylase inhibitor trichostatin A. Hence, epigenetic modifications are believed to occur during prenatal and postnatal life, either due to stochastic events or external environmental factors, and thus to be obvious candidate molecular mechanisms for phenotypic variation. It is not currently known whether epigenetic modifications may regulate gene expression in humans who have been exposed to an adverse environment, whether such changes may be present throughout the entire life span or whether prenatal operating factors may influence the rate of the age related changes.

\section{MOLECULAR BASIS OF TWIN DISCORDANCE}

The interaction between environmental factors and phenotypic discordance within $\mathrm{MZ}$ twins has for obvious reasons been noticed many years ago (31). However, very little has been known about the molecular mechanisms by which environmental factors permanently (or perhaps transiently) may influence gene function. At the beginning of the 1980s, scientists started to characterize a new chemical modification-DNA methylation - that is involved in the control of gene expression and is deregulated in cancer (32). This chemical modification was considered to be an "epi"-genetic modification because it provides an additional level of modulation to the genetic code. Today, it is accepted that epigenetics spans the range of heritable changes in gene function and chromatin structure that occur without a change in the DNA sequence. The best-known epigenetic modifications are DNA methylation and histone modifications. Both chemical modifications are stable because they can be transmitted in mitosis but are also relatively easy to modulate, as demonstrated by the huge amount of enzymes present in the cells that catalyze epigenetic modifications. That gene function and chromatin structure can be modulated by means of plastic chemical modifications in the DNA and the accompanying histones and that these modifications can be affected by environmental factors (33-35) make the idea that environmental effects can provoke 
epigenetically mediated phenotypic responses very attractive. However, the precise mechanism by which the environment generates phenotypic adaptive responses is still largely unknown and represents another fascinating area for future research.

\section{CONCEPT OF DIFFERENT "EPIGENOTYPES"}

DNA methylation and histone modification are both essential for metazoan development because they are used by the cell to create a variety of patterns of gene expression and chromatin structures essential for cell function. Thus, a superior organism can be considered to be composed of multiple "cellular epigenotypes," probably as many as there are different cell types. Apart from cell-specific epigenetic patterns, epigenetics also varies among individuals. In fact, when global DNA methylation levels from the same tissue type in a group of individuals are compared, the levels are found not to be uniform $(16,36)$, implying the existence of different epigenotypes in distinct organisms. These observations raise the questions of when these epigenetic differences are established during ontogenic development, and whether they are transmitted to future generations.

In the case of the first question, if sexual reproduction can produce not only unique genotypes, but also unique epigenotypes, then epigenetic variability must be acquired during ontogenic development. Unfortunately, there are few experimental data that address this matter, although our recent study comparing epigenetics in MZ twins (16) provides indirect evidence. We found that young twins were epigenetically identical but also very different within pairs, which suggests that epigenetic variability is already present at early developmental stages and that there may be a strong component of the progenitors in establishing the initial epigenotype at birth. This connects with the second question about whether epigenetic modifications are transmitted to the next generation. This is a controversial matter because, on one hand, there is experimental evidence from inbred mouse models of the transgenerational persistence of DNA methylationdependent phenotypes (37), while on the other hand, it is well known that during sexual reproduction "epigenetic reprogramming" takes place, which consists of the practical removal of all methylation from the cell (38). Thus, our concern becomes how the DNA methylation patterns can be inherited under a context of complete demethylation. Further research in animal models is required to clarify this issue definitively. The appropriate experiments would compare global and locus-specific epigenetic characteristics of newborn mice with their progenitors to evaluate the degree of sexual transmission of epigenetic patterns, and to determine whether new and unique epigenetic combinations are generated. Epigenetic reprogramming during mammalian development, and the inheritance of an acquired epigenetic status, are probably among the most challenging ideas in modern biology, since the possibility that environmentally mediated epigenetic adaptations have an impact on future generations has enormous conceptual ramifications.

\section{EPIGENETIC DRIFT DURING AGING}

It is well known that specific epigenetic changes are associated with aging. Early studies of global DNA methylation revealed a reduction in methylcytosine in various mammalian tissues $(39,40)$. However, in multicellular organisms, changes in global DNA methylation levels during ageing must be interpreted taking into account two critical factors: the DNA region and cell type in which they occur. Epigenetics in general, and DNA methylation in particular, are the most important molecular mechanisms determining cell fate and tissue specificity. Indeed, DNA methylation is cell-type dependent (41). Thus, in the case of epigenetic changes during ontogenic development, it is important to bear in mind that the epigenetic changes and their biologic significance can vary greatly with tissue type. For example, various tissues, including peripheral leukocytes, feature a global decrease in DNA methylation with age (42), while other tissues do not change (43). Epigenetic studies of complex tissues are required to establish the relative proportions of cell populations with and without changes in DNA methylation over time. In addition, target tissues with known direct involvement in key disease processes are an ultimate demand in studies addressing a potential role of epigenetic modifications in various diseases.

Having stated that the DNA methylation changes are dependent on the cell type because each cell type has its own basal methylation level, and that these levels may also vary among individuals, it is important to note that even when there is a net loss of global methylation in some cell types and within specific contexts, this does not entail a loss of methylcytosine in the whole genome. In fact, there are DNA regions, such as ribosomal DNA clusters, that become hypermethylated during ageing (44). So, what are the biologic significance and consequences of the global demethylation of the genome? Our study of MZ twins provides some clues. If we look at the methylation status of repeated DNA in 50-y-old twins, we can see that both siblings of older twins have constitutively lower methylation levels than do those of younger twins and that one of the oldest has extremely low methylation levels in these regions. Similar age-related losses of methylation of repeated DNA have also been reported in mouse (45-48). If the role of DNA methylation in these repeated DNA regions is to maintain a condensed-repressed chromatin state (49), thereby reducing transcriptional noise (50), we may hypothesize that the molecular mechanism responsible for maintaining the hypermethylated status of these regions becomes less effective with age, that this effect is much stronger in some individuals than in others, and that the efficiency of the methylation machinery is independent of the genotype due to the changes that cause the differences between MZ twins (16).

Considering all these matters together, although it is clear that there is generally a global loss of methylation as mammals age, the basal levels of different individuals are very different. This is consistent with the concept of "epigenotypes" (interindividual variation) and is not contradicted by the observation that some older individuals are more methylated than are younger people, since the DNA methylation levels of the older individuals were probably higher at birth than were those of the younger individuals. As it is not possible to analyze the $\mathrm{mC}$ levels over complete human lifetimes, we can only resolve this matter using animal models. However, these might pose problems of their own: the 
shorter lifespan of mice (for example) might affect the conclusions about aging-dependent epigenetic variation.

We are also interested in establishing how epigenetic variability is generated during ontogenic development. It has been proposed that epigenetic changes during ontogenic development are determined by the environment or are stochastic $(34,35,51)$. In fact, the changes probably result from a combination of the two processes. There is much direct and indirect experimental evidence supporting the environmental cause. For instance, it has been demonstrated that specific care of young rats by their mothers can cause epigenetic changes in the glucocorticoid receptor (33). Similarly, diets deficient in nutrients important for the epigenetic metabolism like folate, choline, and methionine are associated with genome-wide hypomethylation $(52,53)$, and with the development of cancer (54), Parkinson's (55) and Alzheimer's (56) diseases. The close association between the percentage of the lifetime shared by MZ twins and their epigenetic concordance (16) also suggests a strong effect of environmental factors on the epigenetic modifications. However, there are several epigenetic changes during ontogenic development that cannot be explained by environmental effects alone (57). These epigenetic variations have been postulated as being stochastic (57). The existence of a stochastic component of epigenetic variability is strongly supported by experiments with inbred mice (which are virtually twins after several generations) under almost identical environmental conditions-something impossible to achieve with human models (58). These experiments demonstrated that, apart from the environment, phenotypic variability must be attributed to a "third component," which can be considered the result of a kind of stochastic "epigenetic recombination" after sexual reproduction. The hypothesis of the "third component" is consistent with the concept of multiple epigenotypes and could explain the different epigenetic patterns found even between young individuals (16).

\section{NORMAL AND DISEASE PHENOTYPES VERSUS NORMAL AND DISEASE EPIGENOTYPES}

The relationship between phenotype and epigenetics has been extensively described in the previous sections. This relationship is even more evident in disease phenotypes: aberrant hypermethylation of $\mathrm{CpG}$ islands located in the promoter regions of tumor suppressor genes is one of the most important mechanisms of improper gene inactivation in cancer (59). Apart from cancer, an increasing number of other diseases are being found to be caused by aberrant epigenetic functioning, including atherosclerosis (60), osteoarthritis (61), lupus erythematosus (62), imprinting disorders (63), and neuropsychiatric disorders (64).

Sometimes the relationship between an adverse environmental condition, epigenetic alterations, and disease is quite evident. For instance, it was recently reported that the promoter region of the tumor suppressor gene p16 is frequently hypermethylated even in normal cells of smokers (65). However, in most cases, the association between abnormal epigenetic modifications and disease is not so clear and it is in these intermediate situations that the definition of the "disease epigenotypes" is truly challenging. A good illustration of this is the observation that one of the siblings of 50-y-old twins from our study (16) had lower DNA methylation levels in repeated DNA than did his brother. The lower levels were associated with the overexpression of repeated DNA sequences that must be repressed in healthy cells. Intriguingly, the sibling with the DNA methylation defects exhibited a marked disease phenotype, including of cardial incompetence, gout, acute myocardial infarction, hypertension, and diabetes. Further research is needed to establish the mechanistic relationship between the disease phenotype and epigenotype of this twin.

Several twin studies, mainly investigating mental diseases such as bipolar disorders and schizophrenia $(14,51,66)$, have focused on the epigenetic differences in discordant MZ twins. It is currently unknown whether epigenetic modification represents a key determinant of type 2 diabetes. The development and natural history of type 2 diabetes is age-related-the incidence increases with age and the severity of metabolic defects increases with time-and is consistent with a putative role for accumulating age-related epigenetic modifications in the pathogenesis of type 2 diabetes. Epigenetic modifications add an additional layer of complexity to the process of translating DNA code to its end product (i.e. structural and functional proteins), and may explain the failure to identify causal genes of complex diseases, including type 2 diabetes. Furthermore, the incomplete penetrance of susceptibility genes and variation in phenotype (severity of disease) in genetically predisposed individuals may in part be explained by differences in epigenetic regulation and gene expression $(9,57)$. Some indication of a subtle role for DNA methylation in type 2 diabetes comes from a study demonstrating reduced S-adenosylmethionine, the main physiologic donor of methyl groups, in diabetic patients (67). Other studies have concluded a role for DNA methylation in regulating the expression of glucose transporter 4 and leptin genes during adipocyte differentiation $(68,69)$. However, these studies are merely suggestive, and much remains to be resolved. MZ twins discordant for type 2 diabetes constitute an excellent model for investigating whether phenotypic differences are associated with differences in global and gene-specific epigenetic profiles. Future studies identifying epigenetically regulated target genes in target tissues of insulin resistance (ie skeletal muscle and adipose tissue), representing an early (or the earliest) defect of metabolism in Type 2 diabetes, may provoke a major break through, or even paradigm shift, in our understanding of the molecular mechanisms underlying this disease.

\section{REFERENCES}

1. Poulsen P, Kyvik KO, Vaag A, Beck-Nielsen H 1999 Heritability of type II (non-insulin-dependent) diabetes mellitus and abnormal glucose tolerance-a population-based twin study. Diabetologia 42:139-145

2. Gatz M, Reynolds CA, Fratiglioni L, Johansson B, Mortimer JA, Berg S, Fiske A, Pedersen NL 2006 Role of genes and environments for explaining Alzheimer disease. Arch Gen Psychiatry 63:168-174

3. Mack TM, Hamilton AS, Press MF, Diep A, Rappaport EB 2002 Heritable breast cancer in twins. Br J Cancer 87:294-300

4. Page WF, Braun MM, Partin AW, Caporaso N, Walsh P 1997 Heredity and prostate cancer: a study of World War II veteran twins. Prostate 33:240-245

5. Barnett AH, Eff C, Leslie RD, Pyke DA 1981 Diabetes in identical twins. A study of 200 pairs. Diabetologia 20:87-93

6. Altshuler D, Hirschhorn JN, Klannemark M, Lindgren CM, Vohl MC, Nemesh J, Lane CR, Schaffner SF, Bolk S, Brewer C, Tuomi T, Gaudet D, Hudson TJ, Daly M, 
Groop L, Lander ES 2000 The common PPARgamma Pro12Ala polymorphism is associated with decreased risk of type 2 diabetes. Nat Genet 26:76-80

7. Ek J, Andersen G, Urhammer SA, Gaede PH, Drivsholm T, Borch-Johnsen K, Hansen T, Pedersen O 2001 Mutation analysis of peroxisome proliferator-activated receptor-gamma coactivator-1 (PGC-1) and relationships of identified amino acid polymorphisms to Type II diabetes mellitus. Diabetologia 44:2220-2226

8. Grant SF, Thorleifsson G, Reynisdottir I, Benediktsson R, Manolescu A, Sainz J, Helgason A, Stefansson H, Emilsson V, Helgadottir A, Styrkarsdottir U, Magnusson KP, Walters GB, Palsdottir E, Jonsdottir T, Gudmundsdottir T, Gylfason A, Saemundsdottir J, Wilensky RL, Reilly MP, Rader DJ, Bagger Y, Christiansen C, Gudnason V, Sigurdsson G, Thorsteinsdottir U, Gulcher JR, Kong A, Stefansson K 2006 Variant of transcription factor 7-like 2 (TCF7L2) gene confers risk of type 2 diabetes. Nat Genet 38:320-323

9. Bjornsson HT, Fallin MD, Feinberg AP 2004 An integrated epigenetic and genetic approach to common human disease. Trends Genet 20:350-358

10. Gringras P, Chen W 2001 Mechanisms for differences in monozygous twins. Early Hum Dev 64:105-117

11. Singh SM, Murphy B, O'Reilly R 2002 Epigenetic contributors to the discordance of monozygotic twins. Clin Genet 62:97-103

12. Kato T, Iwamoto K, Kakiuchi C, Kuratomi G, Okazaki Y 2005 Genetic or epigenetic difference causing discordance between monozygotic twins as a clue to molecular basis of mental disorders. Mol Psychiatry 10:622-630

13. Oates NA, van Vliet J, Duffy DL, Kroes HY, Martin NG, Boomsma DI, Campbell M, Coulthard MG, Whitelaw E, Chong S 2006 Increased DNA methylation at the AXIN1 gene in a monozygotic twin from a pair discordant for a caudal duplication anomaly. Am J Hum Genet 79:155-162

14. Petronis A, Gottesman II, Kan P, Kennedy JL, Basile VS, Paterson AD, Popendikyte V 2003 Monozygotic twins exhibit numerous epigenetic differences: clues to twin discordance? Schizophr Bull 29:169-178

15. Mill J, Dempster E, Caspi A, Williams B, Moffitt T, Craig I 2006 Evidence for monozygotic twin (MZ) discordance in methylation level at two $\mathrm{CpG}$ sites in the promoter region of the catechol-O-methyltransferase (COMT) gene. Am J Med Genet B Neuropsychiatr Genet 141:421-425

16. Fraga MF, Ballestar E, Paz MF, Ropero S, Setien F, Ballestar ML, Heine-Suner D, Cigudosa JC, Urioste M, Benitez J, Boix-Chornet M, Sanchez-Aguilera A, Ling C, Carlsson E, Poulsen P, Vaag A, Stephan Z, Spector TD, Wu YZ, Plass C, Esteller M 2005 Epigenetic differences arise during the lifetime of monozygotic twins. Proc Natl Acad Sci U S A 102:10604-10609

17. Hales CN, Barker DJ 1992 Type 2 (non-insulin-dependent) diabetes mellitus: the thrifty phenotype hypothesis. Diabetologia 35:595-601

18. Ravelli AC, van der Meulen JH, Michels RP, Osmond C, Barker DJ, Hales CN, Bleker OP 1998 Glucose tolerance in adults after prenatal exposure to famine. Lancet 351:173-177

19. Bavdekar A, Yajnik CS, Fall CH, Bapat S, Pandit AN, Deshpande V, Bhave S, Kellingray SD, Joglekar C 1999 Insulin resistance syndrome in 8-year-old Indian children: small at birth, big at 8 years, or both? Diabetes 48:2422-2429

20. Hattersley AT, Tooke JE 1999 The fetal insulin hypothesis: an alternative explanation of the association of low birthweight with diabetes and vascular disease. Lancet 353:1789-1792

21. Poulsen P, Vaag AA, Kyvik KO, Moller Jensen D, Beck-Nielsen H 1997 Low birth weight is associated with NIDDM in discordant monozygotic and dizygotic twin pairs. Diabetologia 40:439-446

22. Poulsen P, Levin K, Beck-Nielsen H, Vaag A 2002 Age-dependent impact of zygosity and birth weight on insulin secretion and insulin action in twins. Diabetologia 45:1649-1657

23. Poulsen P, Vaag A 2006 The intrauterine environment as reflected by birth size and twin and zygosity status influences insulin action and intracellular glucose metabolism in an age- or time-dependent manner. Diabetes 55:1819-1825

24. Lucas A 1991 Programming by early nutrition in man. Ciba Found Symp 156:38-50

25. McMillen IC, Robinson JS 2005 Developmental origins of the metabolic syndrome: prediction, plasticity, and programming. Physiol Rev 85:571-633

26. Gallou-Kabani C, Junien C 2005 Nutritional epigenomics of metabolic syndrome: new perspective against the epidemic. Diabetes 54:1899-1906

27. Simmons R 2005 Developmental origins of adult metabolic disease: concepts and controversies. Trends Endocrinol Metab 16:390-394

28. Lillycrop KA, Phillips ES, Jackson AA, Hanson MA, Burdge GC 2005 Dietary protein restriction of pregnant rats induces and folic acid supplementation prevents epigenetic modification of hepatic gene expression in the offspring. J Nutr 135:1382-1386

29. Fu Q, McKnight RA, Yu X, Callaway CW, Lane RH 2006 Growth retardation alters the epigenetic characteristics of hepatic dual specificity phosphatase 5. FASEB J 20:2127-2129

30. Weaver IC, Meaney MJ, Szyf M 2006 Maternal care effects on the hippocampal transcriptome and anxiety-mediated behaviors in the offspring that are reversible in adulthood. Proc Natl Acad Sci U S A 103:3480-3485

31. Wilson RS 1978 Synchronies in mental development: an epigenetic perspective. Science 202:939-948

32. Feinberg AP, Tycko B 2004 The history of cancer epigenetics. Nat Rev Cancer 4:143-153

33. Weaver IC, Cervoni N, Champagne FA, D'Alessio AC, Sharma S, Seckl JR, Dymov S, Szyf M, Meaney MJ 2004 Epigenetic programming by maternal behavior. Nat Neurosci 7:847-854

34. Feil R 2006 Environmental and nutritional effects on the epigenetic regulation of genes. Mutat Res 600:46-57

35. Jaenisch R, Bird A 2003 Epigenetic regulation of gene expression: how the genome integrates intrinsic and environmental signals. Nat Genet 33:245-254
36. Stach D, Schmitz OJ, Stilgenbauer S, Benner A, Dohner H, Wiessler M, Lyko F 2003 Capillary electrophoretic analysis of genomic DNA methylation levels. Nucleic Acids Res 31:E2

37. Morgan HD, Sutherland HG, Martin DI, Whitelaw E 1999 Epigenetic inheritance at the agouti locus in the mouse. Nat Genet 23:314-318

38. Reik W, Dean W, Walter J 2001 Epigenetic reprogramming in mammalian development. Science 293:1089-1093

39. Wilson VL, Jones PA 1983 DNA methylation decreases in aging but not in immortal cells. Science 220:1055-1057

40. Wilson VL, Smith RA, Ma S, Cutler RG 1987 Genomic 5-methyldeoxycytidine decreases with age. J Biol Chem 262:9948-9951

41. Flanagan JM, Popendikyte V, Pozdniakovaite N, Sobolev M, Assadzadeh A, Schumacher A, Zangeneh M, Lau L, Virtanen C, Wang SC, Petronis A 2006 Intra- and interindividual epigenetic variation in human germ cells. Am J Hum Genet 79:67-84

42. Fuke C, Shimabukuro M, Petronis A, Sugimoto J, Oda T, Miura K, Miyazaki T, Ogura C, Okazaki Y, Jinno Y 2004 Age related changes in 5-methylcytosine content in human peripheral leukocytes and placentas: an HPLC-based study. Ann Hum Genet 68:196-204

43. Tawa R, Ueno S, Yamamoto K, Yamamoto Y, Sagisaka K, Katakura R, Kayama T, Yoshimoto T, Sakurai H, Ono T 1992 Methylated cytosine level in human liver DNA does not decline in aging process. Mech Ageing Dev 62:255-261

44. Oakes CC, Smiraglia DJ, Plass C, Trasler JM, Robaire B 2003 Aging results in hypermethylation of ribosomal DNA in sperm and liver of male rats. Proc Natl Acad Sci U S A 100:1775-1780

45. Mays-Hoopes L, Chao W, Butcher HC, Huang RC 1986 Decreased methylation of the major mouse long interspersed repeated DNA during aging and in myeloma cells. Dev Genet 7:65-73

46. Barbot W, Dupressoir A, Lazar V, Heidmann T 2002 Epigenetic regulation of an IAP retrotransposon in the aging mouse: progressive demethylation and de-silencing of the element by its repetitive induction. Nucleic Acids Res 30:2365-2373

47. Hornsby PJ, Yang L, Gunter LE 1992 Demethylation of satellite I DNA during senescence of bovine adrenocortical cells in culture. Mutat Res 275:13-19

48. Ono T, Shinya K, Uehara Y, Okada S 1989 Endogenous virus genomes become hypomethylated tissue-specifically during aging process of C57BL mice. Mech Ageing Dev 50:27-36

49. Bestor TH, Tycko B 1996 Creation of genomic methylation patterns. Nat Genet 12:363-367

50. Richardson B 2003 Impact of aging on DNA methylation. Ageing Res Rev 2:245-261

51. Petronis A 2006 Epigenetics and twins: three variations on the theme. Trends Genet $22 \cdot 347-350$

52. Niculescu MD, Zeisel SH Diet, methyl donors and DNA methylation: interaction between dietary folate, methionine and choline. J Nutr 2002;132:2333S-2335S

53. Poirier LA The effects of diet, genetics and chemicals on toxicity and aberrant DNA methylation: an introduction. J Nutr 2002;132:2336S-2339S

54. Wainfan E, Dizik M, Stender M, Christman JK 1989 Rapid appearance of hypomethylated DNA in livers of rats fed cancer-promoting, methyl-deficient diets. Cancer Res 49:4094-4097

55. Duan W, Ladenheim B, Cutler RG, Kruman II, Cadet JL, Mattson MP 2002 Dietary folate deficiency and elevated homocysteine levels endanger dopaminergic neurons in models of Parkinson's disease. J Neurochem 80:101-110

56. Kruman II, Kumaravel TS, Lohani A, Pedersen WA, Cutler RG, Kruman Y, Haughey N, Lee J, Evans M, Mattson MP 2002 Folic acid deficiency and homocysteine impair DNA repair in hippocampal neurons and sensitize them to amyloid toxicity in experimental models of Alzheimer's disease. J Neurosci 22:1752-1762

57. Wong AH, Gottesman II, Petronis A 2005 Phenotypic differences in genetically identical organisms: the epigenetic perspective. Hum Mol Genet 14:R11-R18

58. Gartner K 1990 A third component causing random variability beside environment and genotype. A reason for the limited success of a 30 year long effort to standardize laboratory animals? Lab Anim 24:71-77

59. Esteller M $2002 \mathrm{CpG}$ island hypermethylation and tumor suppressor genes: a booming present, a brighter future. Oncogene 21:5427-5440

60. Lund G, Andersson L, Lauria M, Lindholm M, Fraga MF, Villar-Garea A, Ballestar E, Esteller M, Zaina S 2004 DNA methylation polymorphisms precede any histological sign of atherosclerosis in mice lacking apolipoprotein E. J Biol Chem 279:29147-29154

61. Roach HI, Aigner T 2007 DNA methylation in osteoarthritic chondrocytes: a new molecular target. Osteoarthritis Cartilage 15:128-137

62. Ballestar E, Esteller M, Richardson BC 2006 The epigenetic face of systemic lupus erythematosus. J Immunol 176:7143-7147

63. Feinberg AP, Ohlsson R, Henikoff S 2006 The epigenetic progenitor origin of human cancer. Nat Rev Genet 7:21-33

64. Lokk J 2003 News and views on folate and elderly persons. J Gerontol A Biol Sci Med Sci 58:354-36

65. von Zeidler SV, Miracca EC, Nagai MA, Birman EG 2004 Hypermethylation of the p16 gene in normal oral mucosa of smokers. Int J Mol Med 14:807-811

66. Tsujita T, Niikawa N, Yamashita H, Imamura A, Hamada A, Nakane Y, Okazaki Y 1998 Genomic discordance between monozygotic twins discordant for schizophrenia. Am J Psychiatry 155:422-424

67. Poirier LA, Brown AT, Fink LM, Wise CK, Randolph CJ, Delongchamp RR, Fonseca VA 2001 Blood S-adenosylmethionine concentrations and lymphocyte methylenetetrahydrofolate reductase activity in diabetes mellitus and diabetic nephropathy. Metabolism 50:1014-1018

68. Yokomori N, Tawata M, Onaya T 1999 A transcriptional repressor regulates mouse GLUT4 gene expression during the differentiation of 3T3-L1 cells. Diabetes 48:24712474

69. Yokomori N, Tawata M, Onaya T 2002 DNA demethylation modulates mouse leptin promoter activity during the differentiation of 3T3-L1 cells. Diabetologia 45:140-148 